\title{
A Comparative Analysis of the Online Scheduling SYSTEM
}

\author{
Noor Asma Husain* \\ Centre for Degree and Foundation Studies, School of Professional and Continuing Education \\ Universiti Teknologi Malaysia, Skudai, Johor \\ Malaysia \\ asma@utmspace.edu.my
}

\section{Siti Musleha Ab Mutalib}

Centre for Degree and Foundation Studies, School of Professional and Continuing Education Universiti Teknologi Malaysia, Skudai, Johor Malaysia sitimusleha@utmspace.edu.my

Noor Hayati Mohd Zain

Centre for Degree and Foundation Studies, School of Professional and Continuing Education Universiti Teknologi Malaysia, Skudai, Johor Malaysia noorhayati@utmspace.edu.my

\section{Nor Hidayah Mohd Nor Hussain}

Centre for Degree and Foundation Studies, School of Professional and Continuing Education Universiti Teknologi Malaysia, Skudai, Johor Malaysia norhidayah@utmspace.edu.my

\section{Mohd Khalid Mokhtar}

Lestari Technology Enterprise

Universiti Teknologi Malaysia, Johor Bahru, Johor Malaysia

khalmokh@me.com

\section{Nurul Iman Nor Hisham}

Lestari Technology Enterprise

Universiti Teknologi Malaysia, Johor Bahru, Johor

Malaysia

nuruliman2809@gmail.com

\section{*Corresponding Author email: asma@utmspace.edu.my}

Submission: 10 April 2021

Revised: 15 May 2021

Accepted: 29 May 2021

Peer-review under responsibility of 5th ASIA International Multidisciplinary Conference 2021 (Online)

Scientific Committee

http://connectingasia.org/scientific-committee/

(c) 2021 Published by Readers Insight Publisher,

Office \# 6, First Floor, A \& K Plaza, Near D Watson, F-10 Markaz, Islamabad. Pakistan, editor@readersinsight.net

This is an open access article under the CC BY license (http://creativecommons.org/licenses/by/4.0/). 


\section{A B S T R A C T}

Scheduling system is developed based on customers, individuals or organizational preferences in order to create an efficient and effective management of arrangement in prioritization, tasks, place and time. Some of scheduling systems will integrate a database for effective access of editing, viewing and recording amount of data. However, poor scheduling practices would cause undesirable time redundancy and inefficient process just to schedule a timetable for the lecturers and students. Poor scheduling also can cause a misunderstanding between lectures such as double-assignations of lectures, cancellations of presentations, clash in class schedule, prolonged postponement as well as inefficiency in terms of resources and time. A good scheduling system could generate optimal presentation of timetables and enable a direct interaction between lecturers and administration staff that will take into account all the constraints such as to check availability of time and place of events and real-time updates that will help data handling accuracy, cost effective and efficient time management. Therefore, this study will make a comparison and execute a standard process of scheduling framework for future practice in academic industry. This paper presents a practical method for making a comparison based on the studies on existing scheduling system.

Keywords: Educational Timetabling, Scheduling System, Comparative Analysis, Online System

\section{R E S E A R C H H I G H L I G H T S}

Educational timetabling, scheduling system, comparative analysis, online system.

In education industry, scheduling would be compulsory to arrange lesson schedule for the students at the beginning of each semester (1). A schedule for learning will be allocated to a period of time by administrators, while teachers will prepare the lesson design according to their amount of instructional time (2). Research shows that effective scheduling does promote and improve students' academic achievements and improve time management (3). Therefore, this study highlights a comparison and executes a standard process of scheduling framework for future practice in academic industry by presenting a conceptual framework for an online automated scheduling system. This paper also presents a practical method for making a comparison based on the studies on the existing scheduling system based on four elements in scheduling system which are the objectives, methods, constraints and solution tools when implementing a scheduling system.

\section{Research Objectives}

Scheduling is also considered as allocating resources to a series of tasks in the most effective way over time especially when it is essential for management and educational processes to keep track of related tasks within a specific period (4). However, constraints always occur when setting up and plan for the entire semester which is complex and timeconsuming to avoid clashes between classes. Thus, this reasearch aims to make a comparative analysis by making a comparison and executing a standard process of scheduling framework for future practice in academic industry. This research also presents a practical method for making a comparison based on the studies on existing scheduling system by analyzing the integration of four elements which are the objectives, methods, constraints and solution tools. By understanding and making a comparison analysis on 
existing scheduling system, we will be able to comprehend the process development that has been carried out to create a scheduling system.

\section{Methodology}

The proposed conceptual framework of an automatic scheduling management system that specialised in administration for faculties to organise classes and lecturers, manage timetables and organise university programmes is a web-based system. The approach used in this conceptual framework was proposed to ensure data handling and synchronization update through a server with an internet connection. The system users will be required to log in to the automated scheduling system using a web-based platform to access, book and track. By logging in, the system will go to the cloud database which is the SQL Server that acts as Database Management System (DBMS), for the user to store, retrieve, update, record and delete any information in the server. The development of the web application of Scheduling System will require a PHP scripting, CSS coding and HTML interface that will execute a User Interface which is the website. On the website, the system users will be able to manage user profile, make and manage data maintenance, make a booking, manage and schedule a class, course and planning throughout the semester. The system would also send a notification error if any clashes of events have been made. Below is the proposed framework for the web-based Scheduling System.

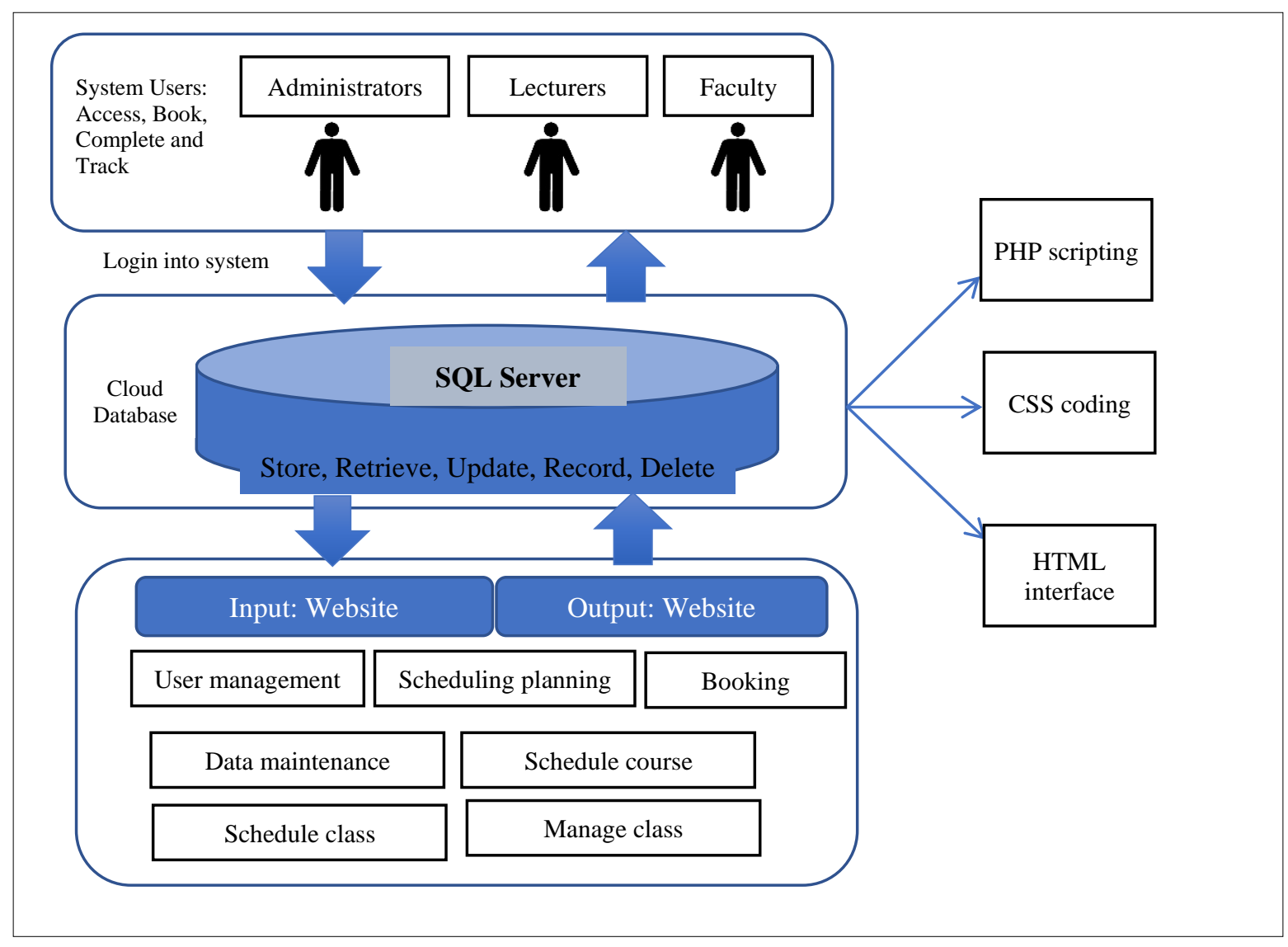




\section{Results \& Findings}

From the comparison that has been made on the existing scheduling system, some of the research in scheduling system also focuses on the algorithm used to improve the scheduling process. Given the different elements to be adapted to solve the complexity of issues, some aspects of elements constituting in the scheduling system are identified which are the objectives, methods, constraints and solution tools for the existing scheduling system. According to research, the scheduling system is a combination of models, tools and methods including a human scheduler involved in the process (5). All problems have solutions that need to be implemented for successful adaptation of objectives, methods of approach and constraints for the scheduling system. Research from Fiarni et al., (6), implemented a web-based design platform for its automatic scheduling system approach in handling collaborative function that can be accessed at any time and everywhere as long as the gadgets have a web browser such as computers (PCs), laptops, smartphones tablets, etc (6). For the solution tools used in the research by Framinan et al., (5), they planned for the development of a manufacturing scheduling software tool that will need an installation on their computers. The scheduling system can be applied through database implemented by using web application program language PHP and database management system MySQL (7). Since there is an improvement in internet networking and technologies, accessing internet networking no longer becomes a major problem for users to access the internet at any time and anywhere. Moreover, for a web-based scheduling system, the implementation of Rapid Application Development technique is also proposed as an incremental model that integrates with google drive and link with external database using Apache web server connection and SQL as DBMS (8).

\section{Acknowledgement}

This research was funded by the UTMSPACE through Potential Development Fund, Research Grant Scheme managed by Research Management Unit of UTMSPACE Vot No. SP-PDF2011.

\section{References}

1. Saptarini NGAPH, Suasnawa IW,Ciptayani PI. Senior high school course scheduling using genetic algorithm. Journal of Physics: Conference Series, 953(1). 2018. https://doi.org/10.1088/1742-6596/953/1/012067

2. Pedersen JL. The effects of scheduling modes on high school student achievement in lowa, 2001.

3. Childers EA. Effects of Class Scheduling and Student Achievement on State Testing, 2018.

4. Meccawy M. The Brilliant Scheduler: Automated Scheduling System for Video Conferencing Courses. Computer and Information Science. 2018. https://doi.org/10.5539/cis.v11n3p82

5. Framinan JM, Leisten R, \& García RR. Manufacturing scheduling systems: An integrated view on models, methods and tools. Manufacturing Scheduling Systems: An Integrated 
View on Models, Methods and Tools, 9781447162(May 2016), 1-400. https://doi.org/10.1007/978-1-4471-6272-8

6. Fiarni C, Gunawan AS, Ricky, Maharani H,Kurniawan H. Automated Scheduling System for Thesis and Project Presentation Using Forward Chaining Method with Dynamic Allocation Resources. Procedia Computer Science, 72(February 2016), 209-216. https://doi.org/10.1016/j.procs.2015.12.133

7. Abdullah PY, Hussan DBK. Class Scheduling System. Special Collections, September, 2019. https://doi.org/10.13140/RG.2.2.13580.87680

8. Nielsen R. CS651 Computer Systems Security Foundations 3d Imagination Cyber Security Management Plan LA-UR-15-21507 Approved for public release; distribution is unlimited. Intended for: CS651 Computer Systems Security Foundations 3d Imaginat. January, 2015.

\section{Author's Biography for each author}

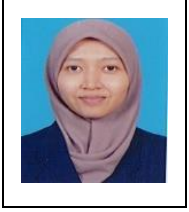

Noor Asma Husain, received her Master of Science (Computer Science) from Universiti Teknologi Malaysia in 2012. She holds a position as a Lecturer at Centre for Degree and Foundation Studies, UTMSPACE. Her research interests are Software Engineering and Image Processing,

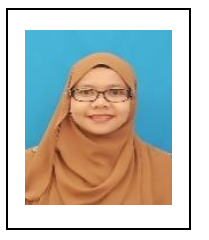

Siti Musleha, received her Master of Science (Mathematic) from Universiti Teknologi MARA in 2017. She holds a position as a Lecturer at Centre for Degree and Foundation Studies, UTMSPACE. Her research interests are Fuzzy Mathematics and Forecasting.

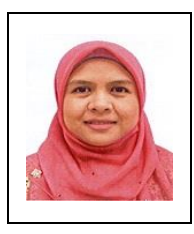

Noor Hayati Mohd Zain, received her Master of Science (Computer Science) from Universiti Teknologi Malaysia in 2012. She holds a position as a Lecturer at Centre for Degree and Foundation Studies, UTMSPACE. Her research interests are Computer Network and Artificial Intelligence.

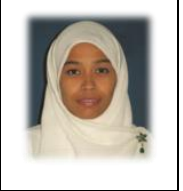

Nor Hidayah Mohd Nor Hussain, received her Bachelor of Science (Business Administration) from Universiti Teknologi MARA in 2005. She holds a position as Senior Academic Executive at Centre for Degree and Foundation Studies, UTMSPACE. Her interest is Management and Administration. 
Mohd Khalid Mokhtar, received his Master by Research in Computer Science from Universiti Teknologi Malaysia in 2017. His major fields of study are computer graphics, visualisation, augmented reality, virtual reality and simulation. Currently, he is pursuing a PhD in Human Computer Interaction.

Nurul Iman Nor Hisham, received her Bachelor in Computer Science (Graphic and Multimedia Software) in 2017. Later, she received her Master of Business Administration from Azman Hashim International Business School, Universiti Teknology Malaysia in 2019. Currently, she is working for Lestari Technology Enterprise. 